\title{
Evidence that Chlamydia trachomatis causes seronegative arthritis in women
}

\author{
D TAYLOR-ROBINSON, ${ }^{\prime}$ B J THOMAS.' J DIXEY.' $M \quad$ F OSBORN.' \\ P M FURR!' AND A C KEAT
}

From the 'Division of Sexually Transmitted Diseases, MRC Clinical Research Centre, Harrow, Middlesex: and 'the Department of Rheumatology, Westminster Hospital, Page Street, London

SUMmARY Chlamydia trachomatis elementary bodies (EBs) were found in synovial membranes or synovial fluid cell deposits from five of 15 women with seronegative mono- or oligoarthritis by means of a fluorescein conjugated anti-chlamydial monoclonal antibody (MicroTrak; Syva). Genital tract specimens were taken from only five of the patients, one of whom had intraarticular EBs, but none was chlamydia positive. Six of 10 patients tested were HLA-B27 positive, and chlamydial IgG antibody, measured by microimmunofluorescence, was present at a titre of $1 / \geqslant 64$ in the sera of five of the 15 patients, three of the five having EBs in their joints. In contrast, chlamydial EBs were not detected in the joints of a control group of 10 other women, most of whom had rheumatoid arthritis. None of them was HLA-B27 positive, and only one had a chlamydial antibody titre of $1 / \geqslant 64$. Neither Mycoplasma hominis nor ureaplasmas were isolated from the synovial fluids of seven patients and five controls who were tested. Antibody to $M$ genitalium, however, was detected in five of the 10 patients but in none of the controls. This evidence apart, there was no other to suggest that mycoplasmas or ureaplasmas might be responsible for arthritis which could not be attributed to chlamydiae.

Key word: mycoplasmas.

Studies on men presenting with sexually acquired reactive arthritis (SARA), ' of whom about one third have the triad of Reiter's syndrome, show that Chlamydia trachomatis organisms (chlamydiae) can be isolated from the urethra of about one third of them and that cellular and antibody responses are enhanced, ${ }^{2-4}$ high titres of chlamydial IgG antibody being detectable in the sera of about half. In addition, in some patients with Reiter's syndrome, in vitro responses of synovial fluid mononuclear cells to chlamydial antigens have been reported to be more enhanced than those of peripheral blood mononuclear cells. ${ }^{5}$ These data suggest that acute $C$ trachomatis genital tract infection is implicated in the development of arthritis in some patients. This has been confirmed recently in a study in which chlamydial elementary bodies were found in the joints of five of eight patients with SARA by using a

Accepted for publication 24 October 1987.

Correspondence to Dr D Taylor-Robinson, Division of Sexually Transmitted Diseases, Clinical Research Centre, Watford Road. Harrow, Middlesex, HAl 3UJ. specific anti-chlamydial fluorescein conjugated monoclonal antibody." The latter observation has stimulated a search for chlamydiae in the joints of patients with other arthritides.

Reactive arthritis associated with genital tract infection is recognised less frequently in women. It is not unusual, however, for young women to develop asymmetrical seronegative oligoarthritis which defies specific diagnostic categorisation. In this study we have recorded women presenting with knee effusions in the absence of other diagnostic features and have investigated the possibility of an underlying chlamydial infection being the primary cause of at least some of these cases. Chlamydiae were sought in synovial membranes and synovial fluids and, when possible, in genital tract secretions, and specific antibody was measured. Evidence for infection by mycoplasmas known to occur in the genital tract was also considered, synovial fluids and some genital samples being examined for the presence of Mycoplasma hominis and Ureaplasma urealyticum organisms (ureaplasmas) and sera for antibodies to $M$ hominis and $M$ genitalium. The 
detection of chlamydiae in the joints of some of the women is reported in this communication.

\section{Patients and methods}

PATIENTS AND CONTROLS

Fifteen women presenting to the rheumatology department of the Westminster Hospital with seronegative (IgM rheumatoid factor negative) inflammatory arthritis were examined clinically. All had mono- or oligoarthritis, including knee involvement, which did not conform to a recognised clinical entity. Their sexual history was recorded; none had any genital tract symptoms, symptomatic individuals having been excluded from the study. None of the patients had received antibiotic treatment in the three months before the study. Ten women, six with rheumatoid arthritis and one each with osteoarthritis, gonococcal arthritis, tuberculosis, and erythema nodosum, constituted a control group.

\section{COLLECTION OF SPECIMENS AND THEIR INVESTIGATION}

Synovial fluid was aspirated under local anaesthesia and kept at room temperature for up to four hours before centrifugation at $600 \mathrm{~g}$ for 10 minutes. The cell deposit in residual fluid was stored at $-70^{\circ} \mathrm{C}$, after which it was thawed, smeared on a MicroTrak (Syva) slide, and fixed in acetone. Synovial biopsy specimens were obtained under local anaesthesia with a Storz arthroscope, snap frozen on a cork block in isopentane, and stored in liquid nitrogen. They were then placed in dry ice and sections cut on a cryostat. These were fixed in acetone and stored at $-70^{\circ} \mathrm{C}$ if not stained immediately. Sections and cell deposits were stained with a fluorescein conjugated monoclonal antibody (MicroTrak; Syva) and examined by fluorescence microscopy. ${ }^{7 x}$
The presence of $C$ trachomatis in the genital tract was sought at presentation in some of the patients but in none of the controls. Cotton wool swabs were used to take specimens from the endocervix. In some patients these were smeared on glass slides, which were examined by direct immunofluorescence (MicroTrak; Syva). ${ }^{8}$ In others the swabs were expressed in sucrose-phosphate transport medium (2SP) containing $10 \%$ heat inactivated fetal calf serum, which was then stored in liquid nitrogen. Subsequently, attempts were made to isolate chlamydiae from these specimens using cycloheximide treated McCoy cells and Giemsa staining, as described previously." The same culture procedure was used to try to isolate chlamydiae from uncentrifuged portions of some of the synovial fluids which had been stored at $-70^{\circ} \mathrm{C}$. In addition, attempts were made to isolate $M$ hominis and ureaplasmas from synovial fluids and from the cervices of some of the patients by techniques described previously. ${ }^{10}$

The titres of IgG antibody to $C$ trachomatis in sera or synovial fluids, or both, taken at presentation of the patients were measured by a modified microimmunofluorescence test. ${ }^{\text {A }}$ A similar procedure using fluorescein labelled antihuman total globulins was employed to measure antibodies to $M$ hominis and $M$ genitalium. ${ }^{12}$

\section{Results}

FEATURES OF PATIENTS AND CONTROLS

The ages of the patients ranged from 19 to 55 years (mean 35.2), and the duration of disease at the time of study ranged from three weeks to 60 months (Table 1). A speculum examination of the lower genital tract of seven of the women did not show any

Table 1 Joint and serological findings in 15 patients with unclassified seronegative arthritis

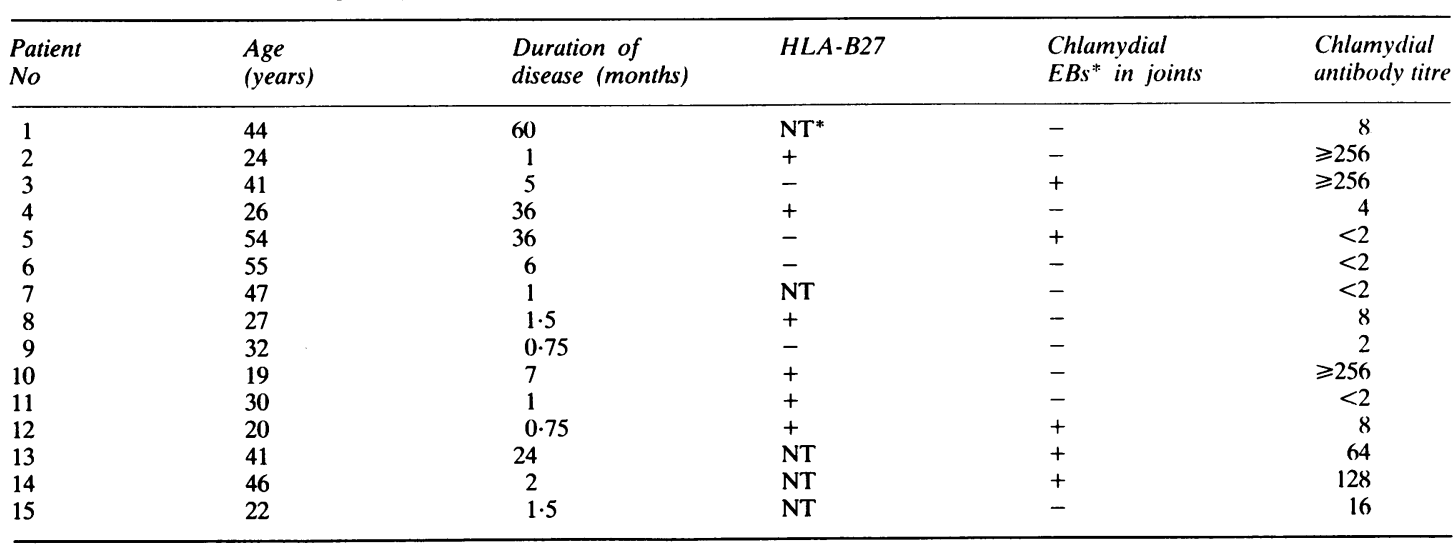

${ }^{*}$ EBs=elementary bodies; NT=not tested. 
Table 2 Summary of findings in patients and controls

\begin{tabular}{|c|c|c|}
\hline & $\begin{array}{l}\text { Putients } \\
(n=15)\end{array}$ & $\begin{array}{l}\text { Controls } \\
(n=10)\end{array}$ \\
\hline Chlamydial EBs in joint material & $5 / 15$ & $0 / 10$ \\
\hline Isolation of chlamydiac from synovial thuid & $0 / 5$ & $0 / 3$ \\
\hline Isolation of chlamydiac from genital tract & $(1) / 5$ & NT \\
\hline Chlamydial antibody titre of $1 / \geqslant 64$ & $5 / 15$ & $(0 / 10$ \\
\hline Isolation of $M$ hominis/urcaplasmas from svnovial fluid & $0 / 7$ & $0 / 5$ \\
\hline Isolation of $M$ hominis/ureaplasmas from genital tract & $2 / 7$ & NT \\
\hline$M$ hominis antibody titre of $1 / 16$ & $3 / 10$ & $2 / 7$ \\
\hline$M$ genitulium antibody titre of $1 / \geqslant 16$ & $5 / 10$ & $0 / 7$ \\
\hline Abnormal genital tract on examination & $0 / 7$ & NT \\
\hline HLA-B27 positive & $6 / 10$ & $0 / 10$ \\
\hline
\end{tabular}

EBs=elementary bodies: $N T=$ not tested.

abnormal features. Six of 10 patients tested were HLA-B27 positive.

The ages of the women in the control group ranged from 24 to 64 years (mean 43.4). All but one had chronic disease and all were HLA-B27 negative.

\section{DETECTION OF CHLAMYDIAE}

Chlamydial elementary bodies (EBs) were detected either in the synovial membrane preparations or the synovial fluid cell deposits from five of the 15 patients with seronegative arthritis (Tables 1 and 2). The EBs were scattered in the membrane sections. whereas they were mostly in groups associated with cells in the synovial fluid cell deposits. In contrast, EBs were not detected in the joints of any of the 10 control women (Table 2).

Attempts to isolate chlamydiae from the synovial fluids of five patients by a culture technique were unsuccessful, the fluids destroying the McCoy cells in two of these instances. Chlamydial EBs had been detected in the joints of three of these patients. Chlamydiae were not isolated from the synovial fluids of three of the controls. Chlamydiae were sought in the cervix of only five patients and were not detected in any of them, though one of the patients had intra-articular EBs.

DETECTION OF CHLAMYDIAL. ANTIBODY IgG antibody at a titre of $1 / \geqslant 64$ was found in the sera or synovial fluids, or both, of five of the 15 patients (Tables 1 and 2), such a titre occurring in three of the five patients in whom chlamydial EBs were detected in the joint. In contrast, antibody at a titre of $1 / \geqslant 64$ was not found in the sera of synovial fluids of any of the 10 controls.

DETECTION OF M HOMINIS AND UREAPLASMAS Attempts were made to isolate $M$ hominis and ureaplasmas from the synovial fluids of seven patients, three of whom had intra-articular chlamydial EBs, but without success (Table 2). Furthermore, neither $M$ hominis nor ureaplasmas were isolated from the synovial fluids of five controls who were tested (Table 2). Two of seven patients tested had ureaplasmas in the lower genital tract. however.

DETECTION OF ANTIBODY TO M HOMINIS AND M GENITALIUM

As shown in Table 2, antibody to $M$ hominis at a titre of $1 / 16$ was found in the sera of three of 10 patients tested (geometric mean (GM) titre of $1 / 7$ ) and in those of two of seven of the controls (GM titre of $1 / 7)$. Antibody to $M$ genitalium at a titre of $1 / \geqslant 16$ was found in the sera of five of the 10 patients (GM titre of $1 / 11$ ) but in none of seven controls (GM titre of $1 / 3$ ). Four of the five patients possessing this antibody did not have EBs detected in their joints.

\section{Discussion}

The finding of chlamydial EBs in the joints of one third of the women with arthritis is strong evidence for an aetiological association. This observation is similar to our recent finding of chlamydial EBs in the joints of patients with SARA. "We were unable to recover viable chlamydiae from the joints of any of the latter patients by a conventional isolation procedure and attempted to do so, also without success, in a few of the patients in the present study. Such failure again raises the question of whether the particles we see are chlamydial EBs or artefacts. Our reasons for believing that they are not artefacts are several-namely, that our experience with the evaluation $^{81.3}$ and use ${ }^{1+}$ of the monoclonal reagent in question is extensive, and that the fluorescing particles have the same features as those seen in the 
genital tract and conjunctivae of patients attending sexually transmitted disease clinics and, indeed, in the joints of patients with SARA. Furthermore, the particles appear exactly like those seen in preparations of mouse joints after experimental inoculation of strain $\mathrm{SA}_{2}$ f of $C$ trachomatis. ${ }^{15}$ and in the present and our previous study" they were not seen in the joints of patients, mostly with rheumatoid arthritis, who served as controls.

It seems clear that a diagnosis of chlamydial infection should be entertained in any sexually active woman who presents with a seronegative mono- or oligoarthritis. There is a chance of confirming the diagnosis rapidly and simply by examining a synovial fluid cell deposit in the way we have described, even when the disease is not of recent onset.

The genital tract may not be the only portal of entry for chlamydiae. C trachomatis infections of the respiratory tract seem to be rare in adults, but $C$ psittaci respiratory infections are now recognised to occur more frequently than thought previously. ${ }^{10}$ The respiratory tract should not, therefore, be forgotten as a possible portal of entry. The monoclonal antibody we used. however, does not enable $C$ psittaci to be detected as the reagent is specific for $C$ trachomatis. Although the genital tract is the most likely site of entry for the chlamydiae found in the joints, we have little information on the occurrence of the organisms in the genital tract of our patients. Asymptomatic infection is an aspect that needs to be examined in a systematic and prospective manner. Chlamydial genital tract infection requires treatment in its own right and, furthermore, should stimulate examination and treatment of sexual partners. Whether early diagnosis of chlamydial joint infection followed by prompt tetracycline or other anti-chlamydial treatment will be helpful in ameliorating the arthritis remains to be seen.

The association between the chlamydial serological findings and the presence or absence of intraarticular EBs is not easy to interpret. We have no clear explanation of why antibody was not detected in two patients in whom intra-articular EBs were found. Conversely, chlamydial antibody in high titre was found in the sera of two women in whom intraarticular chlamydial EBs were not detected. Although it is possible that chlamydiae were implicated in the arthritis in these cases too, a firm diagnosis cannot be made purely on such serological grounds. Indeed, the cause of the arthritis in those women in whom we failed to detect intra-articular EBs is unknown. There are several aspects of this problem that need to be considered. Viable chlamydiae were not recovered from the joints of men in our previous study." nor from those of the women when an attempt was made, so that our failure to $\frac{\mathrm{O}}{\mathrm{c}}$. isolate viable mycoplasmas and ureaplasmas from the joints should be interpreted with caution. Both $\underset{\text { S }}{\overrightarrow{9}}$ ureaplasmas and $M$ hominis have been isolated fromo the joints of hypogammaglobulinaemic patients, ${ }^{17}$ 음 so the existence of these micro-organisms in a non- $\frac{\bar{\omega}}{D}$ viable form in immunocompetent patients should be $\underset{\mathbb{Q}}{\mathbb{Q}}$ contemplated. It will be important to use monoclonal antibodies to search for these microorganisms, and, indeed for others, when such. reagents become available. $M$ hominis and $M \overrightarrow{\vec{\omega}}$ genitalium have been associated with genital tract 0 disease in women, particularly pelvic inflammatory disease. ${ }^{18} 19$ so that seeking antibodies to these mycoplasmas as a pointer to infection by them. seemed worthwhile, especially as few genital tract specimens were available for culture and in view of $\stackrel{\oplus}{G}$ the known difficulty experienced in culturing $M$ ㅇ genitalium. ${ }^{21}$ Antibody to $M$ hominis was distributed equally among the patients and controls, $\rightarrow$ whereas antibody to $M$ genitalium was found more frequently in the patient group. Of course, this could be the result of prior infection with $M \stackrel{\infty}{\infty}$ genitalium rather than reflecting any association with the arthritis and, furthermore, the result could be fortuitous in view of the small number of subjects tested. It is of sufficient interest, however, to warrant a study of a larger number of patients and

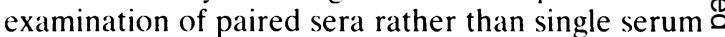
samples in an effort to establish the aetiology of $\overrightarrow{0}$ arthritis which appears not to be of chlamydial origin.

\section{References}

I Keat A C. Maini R N. Nkwazi G C. Pegrum G D. Ridgway G L. Scott J T. Role of Chlamydia trachomatis and HLA-B27 in $\mathrm{O}$ sexually acquired reactive arthritis. $B r$ Med $J$ 1978; i: $6(15-7$.

2 Kousa M. Saikko P. Richmond S. Lassus A. Frequent $O$ association of chlamydial infection with Reiter's sundrome. Sex Transm Dis 1978: 5: 57-61.

3 Keat A C. Thomas B J. Taylor-Robinson D. Pegrum G D. 을 Maini R N. Scott J T. Evidence of Chlamydia trachomatis $N$ infection in sexually acquired reactive arthritis. Ann Rheum Dis o 1980: 39: 431-7.

4 Martin D H. Pollock S. Kuo C-C. Wang S-P. Brunham R C. O Holmes K K. Chlamydia trachomatis infections in men with Reiter's syndrome, Ann Intern Med 1984: 100: 207-13.

5 Ford D K. de Roza D M. Shah P. Cell-mediated immune responses of synovial mononuclear cells to sexually transmitted. enteric and mumps antigens in patients with Reiter's syndrome. rheumatoid arthritis and ankylosing spondvlitis. J Rheumatol $\stackrel{+}{+}$ 1981: 8: 22(1-32.

6 Keat A. Thomas B. Dixey J. Osborn M. Sonnex C. TaylorRobinson D. Chlamydia trachomatis and reactive arthritis- the $\mathbb{D}$ missing link. Lancet 1987: i: 72-4.

7 Tam M R. Stamm W E. Handsficld H H. et al. Culture- $\mathbb{D}$ independent diagnosis of Chlamydia trachomatis using monoclonal antibodies. $N$ Engl J Med 1984: 310: 1146-50.

8 Thomas B J. Evans R T. Hawkins D A. Taylor-Robinson D. 
Sensitivity of detecting Chlamydia trachomatis elementary bodics in smears by use of a fluorescein labelled monoclonal antibody: comparison with conventional chlamydial isolation. $J$ Clin Pathol 1984: 37: 812-6.

9 Thomas B J, Evans R T, Hutchinson G R. Taylor-Robinson D. Early detection of chlamydial inclusions combining use of cycloheximide treated McCoy cells and immunofluorescence staining. J Clin Microbiol 1977; 6: 285-92.

10) Taylor-Robinson D. Furr P M. Recovery and identification of human genital tract mycoplasmas. Isr J Med Sci 1981: 17: 648-53.

11 Thomas B J. Recve P. Oricl J D. Simplificd serological test for antibodics to Chlamydia trachomatis. J Clin Microbiol 1976: 4: 6-10.

12 Furr $P$ M. Taylor-Robinson D. Microimmunofluorescence technique for detection of antibody to Mycoplasma genitalium. J Clin Pathol 1984: 37: 1072-4.

13 Hawkins D A. Wilson R S. Thomas B J. Evans R T. Rapid reliable diagnosis of chlamydial ophthalmia by means of monoclonal antibodics. Br J Ophthalmol 1985: 69: 64(1-4.

14 Thomas B J. Osborn M F. Munday P E. Evans R T. Harris J R W. Taylor-Robinson D. Detection of Chlamydia trachomatis in smears by a fluorescent monoclonal antibody: observal- tions during two vears based on ten thousand patients. Microb Ecol Hlth Dis (in press).

15 Keat A. Thomas B J. Tavlor-Robinson D. Chlamvdial infection in the actiology of arthritis. Br Med Bull 1983: 39: 16\$-74.

16 Grayston J T. Kuo C C. Wang S P. ct al. Clinical findings in TWAR respiratory tract infections. In: Oricl D. Ridgway G. Schachter J. Taylor-Robinson D. Ward M. eds. Chlamidial infections. Cambridge: Cambridge University Press. 1986: $337-40$.

17 Taylor-Robinson D. Thomas B J. Furr P M. Keal A C. The association of Mycoplasma hominis with arthritis. Sex Tramsm Dis 1983: 10 (suppl): 341-4.

18 Taylor-Robinson D. Munday P E. Mvcoplasmal infection of the female genital tract and its complications. In: Hare $M$ J. ed. Genital tract infection in women. Edinburgh: Churchill Livingstonc. 1987.

19 Møller B R. Taylor-Robinson D. Furr P M. Scrological evidence implicating Mycoplasma genitalium in pelvic inflammatory discasc. Lancet 1984: i: 1102-3.

20) Taylor-Robinson D. Furr P M. Hanna N F. Microbiological and serological study of non-gonococcal urethritis with special reference to Mycoplasma genitalium. Genitourin Med 1985: 61: $319-24$. 